\title{
Amyloid $\boldsymbol{\beta}_{\mathbf{2}}$-Microglobulin
}

\section{Yoshihiro Motomiya ${ }^{1 *}$ and Yuichiro Higashimoto ${ }^{2}$}

${ }^{1}$ Suiyukai Clinic, Kashihara, Nara, Japan

2 Department of Chemistry, Kurume University School of Medicine, Kurume, Fukuoka, Japan

*Corresponding author: Yoshihiro Motomiya, Suiyukai Clinic, 676-1 Kuzumoto-cho, Kashihara, Nara, 6340007, Japan, E-mail: motomiya@silver.ocn.ne.jp

Received date: May 24, 2018; Accepted date: June 11, 2018; Published date: June 15, 2018

Citation: Motomiya Y, Higashimoto Y (2018) Amyloid ß2-Microglobulin. J Clin Exp Nephrol Vol.3 No.2: 11. DOI: 10.21767/2472-5056.100062

Copyright: (C2018 Motomiya Y, et al. This is an open-access article distributed under the terms of the Creative Commons Attribution License, which permits unrestricted use, distribution, and reproduction in any medium, provided the original author and source are credited.

\section{Abstract}

Dialysis-related amyloidosis (DRA), which is an inevitable complication of long-term haemodialysis (HD), manifests major clinic-pathological characteristics, including carpal tunnel syndrome, which is the most common clinical sign; systemic involvement of many articular tissues; and the presence of $\beta_{2}$-microglobulin $\left(\beta_{2} \mathrm{M}\right)$ as a precursor protein in this amyloidosis.

Keywords: Dialysis-related amyloidosis; $\beta_{2}$-microglobulin; Haemodialysis

\section{Introduction}

Amyloid is a fibrillar protein and is primarily a conformational variant of an originally globular precursor protein. $\beta_{2} \mathrm{M}$ is an essential protein for normal conformation of major histocompatibility complex class I molecules on cell membranes and is degraded mainly in renal proximal tubules. $\beta_{2} \mathrm{M}$ passes freely across vascular walls. Therefore, serum levels of $\beta_{2} M$ are extremely high in patients undergoing HD. Although HD can clear as much as $70 \%$ of circulating $\beta_{2} \mathrm{M}, \beta_{2} \mathrm{M}$ in the interstitial space can accumulate and progressively lead to development of DRA [1]. The amyloid processes may occur in the interstitial space. We have studied the amyloidogenicity of $\beta_{2} M$ and found a previously unknown amyloidogenic process, which we describe in this short review.

\section{Specific information about the different $\beta_{2} M$ structures follows here:}

The three-dimensional structure (conformation) of $\beta_{2} M: \beta_{2} M$ consists of 99 amino acids. The three-dimensional structure of native $\beta_{2} \mathrm{M}$ is formed by the folding of seven peptide segments (strands) into a globular conformation, with both the $\mathrm{N}$-terminal and the C-terminal segments folded inward from the molecular surface. McParland et al. demonstrated that unfolding in $\beta_{2} \mathrm{M}$ started first in the $\mathrm{N}$-terminal segment and then continued in the C-terminal segment [2].
The intermediate structure of $\boldsymbol{\beta}_{2} \mathbf{M}$ : Several basic studies described a conversion process in which amyloid protein is formed. In this process, the folded conformation, i.e., native $\beta_{2} \mathrm{M}$ is unfolded into a partially unfolded conformer, i.e., the intermediate species. The amyloid protein is insoluble, but the intermediate species is soluble and can be identified directly, with native $\beta_{2} \mathrm{M}$, via capillary electrophoresis. By using this technique [3], we confirmed that $\beta_{2} \mathrm{M}$ in serum consisted of two forms, the folded native $\beta_{2} \mathrm{M}\left(\mathrm{N}-\beta_{2} \mathrm{M}\right)$ and the partially unfolded intermediate $\beta_{2} \mathrm{M}\left(\mathrm{I}-\beta_{2} \mathrm{M}\right)$ in both healthy persons and patients undergoing HD (Figure 1) $[4,5]$.

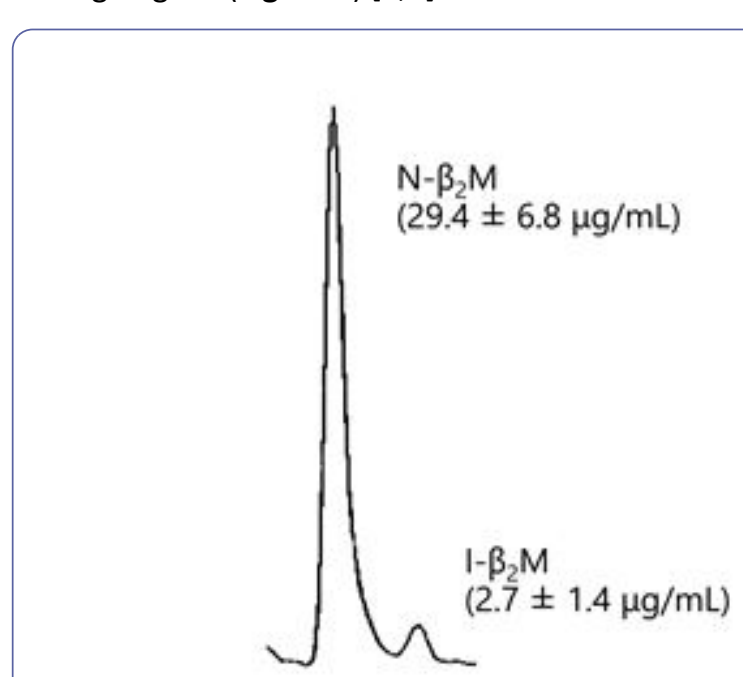

Figure 1: Native $\beta_{2} M\left(N-\beta_{2} M\right)$ and intermediate $\beta_{2} M\left(I-\beta_{2} M\right)$ as determined with capillary electrophoresis. Unpublished data for $n=30$ HD patients.

C-terminal unfolding and $\boldsymbol{\beta}_{2} \mathbf{M}$ 92-99: Stoppini et al. first implicated the $\mathrm{C}$-terminal region of $\beta_{2} \mathrm{M}$ in amyloidogenicity by using a monoclonal antibody specific for the C-terminal eight amino acids [6].We then reported on $\beta_{2} \mathrm{M}$ with an unfolded $\mathrm{C}$ terminal region, i.e., $\beta_{2} \mathrm{M}$ 92-99, in amyloid tissues from patients undergoing HD [7]. However, we did not detect $\beta_{2} \mathrm{M}$ 92-99 in serum from patients undergoing HD because the C-terminal 
region in $\mathrm{I}-\beta_{2} \mathrm{M}$ may be not completely unfolded as is the case for $\beta_{2} \mathrm{M}$ 92-99 [8].

$\Delta \mathbf{N} 6 \boldsymbol{\beta}_{2} \mathbf{M}:$ In 1987 , Linke et al. first reported a variant of $\beta_{2} \mathrm{M}$ lacking the six $\mathrm{N}$-terminal amino acids, i.e., $\Delta \mathrm{N} 6 \beta_{2} \mathrm{M}$, in patients undergoing $\mathrm{HD}$ [9]. Esposito et al. and others then confirmed that $\Delta N 6 \beta_{2} \mathrm{M}$ was a highly amyloidogenic variant $[10,11]$. We recently reported that the $\mathrm{C}$-terminal region was completely unfolded in $\Delta \mathrm{N} 6 \beta_{2} \mathrm{M}$ as well as in $\beta_{2} \mathrm{M}$ 92-99 [8].

Glycosaminoglycans (GAGs) and heparin: GAGs including heparin are an essential component of interstitial tissue. In addition, heparin is most often used as an anti-coagulant in the clinical setting of HD. Several studies showed that GAGs facilitate the amyloidogenicity of $\beta_{2} M[12,13]$, and we also found that heparin promoted $\beta_{2} \mathrm{M}$ unfolding [14].

The working hypothesis: $N-\beta_{2} M$ coexists with I- $\beta_{2} M$ at a ratio of 10:1 in body fluids, and the HD procedure causes a shift from $\mathrm{N}-\beta_{2} \mathrm{M}$ toward $\mathrm{I}-\beta_{2} \mathrm{M}$. GAGs in the interstitial space promote unfolding of the C-terminal region of $\mathrm{I}-\beta_{2} \mathrm{M}$ to generate $\beta_{2} \mathrm{M}$ 92-99. $\beta_{2} \mathrm{M}$ 92-99 cannot be refolded or returned to the vascular space. An accumulation of $\beta_{2} \mathrm{M}$ 92-99 leads to the generation of amyloid $\beta_{2} \mathrm{M}$ in the interstitial space (Figure 2 ).

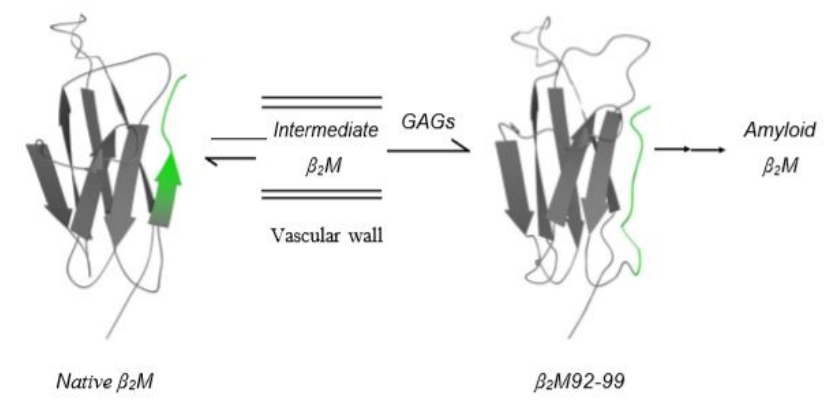

Figure 2: Unfolding processes that leads to formation of amyloid $\beta_{2} \mathrm{M}$.

$\Delta \mathbf{N 6} \boldsymbol{\beta}_{2} \mathbf{M}$ aptamer: We recently showed that an aptamer for $\Delta \mathrm{N} 6 \beta_{2} \mathrm{M}$ has a domain for the C-terminal region and could block amyloid fibril formation in-vitro [15].

\section{Conclusion}

Amyloidosis, including DRA and Alzheimer disease, is becoming a major clinical entity. Amyloidosis is a disease of misfolded precursor proteins. Thus far, we have demonstrated that misfolding of $\beta_{2} \mathrm{M}$ is initiated by an unfolding of the $\mathrm{C}$ terminal segment of $\beta_{2} \mathrm{M}$, and GAGs in interstitial tissue are intimately associated with the completion of the C-terminal unfolding of $\beta_{2} \mathrm{M}$. We believe that an intermediate $\beta_{2} \mathrm{M}$ with an unfolded $\mathrm{C}$-terminal may be a key intermediate molecule for amyloid $\beta_{2} \mathrm{M}$, as (Figure 2) illustrates. The data related to the $\Delta \mathrm{N} 6 \beta_{2} \mathrm{M}$ aptamer support our belief.

\section{References}

1. Strihou YVC, Floege J, Jadoul M (1994) Amyloidosis and its relationship to different dialysis. Nephrol Dial Transplant 9: 156-161.

2. McParland VI, Kalverda AP, Homans SW, Radford SE (2002) Structural properties of an amyloid precursor of $\beta 2$-microglobulin. Nat Struct Biol 9: 326-331.

3. Heegaard NH, Sen JW, Nissen MH (2000) Congophilicity (Congo red affinity) of different $\beta 2$-microglobulin conformations characterized by dye affinity capillary electrophoresis. J Chromatogr A 894: 319-327.

4. Uji $Y$, Motomiya $Y$, Ando $Y$ (2009) A circulating $\beta 2$-microglobulin intermediate in hemodialysis patients. Nephron Clin Pract111: c173-c181.

5. Motomiya Y, Uji Y, Ando Y (2012) Capillary electrophoretic profile of $\beta 2$-microglobulin intermediate associated with hemodialysis. Ther Apher Dial 16: 350-354.

6. Stoppini M, Bellotti V, Mangione P, Ferri G (1997) Use of anti- $\beta 2$ microglobulin mAb to study formation of amyloid fibrils. Eur J Biochem 249: 21-26.

7. Motomiya Y, Ando Y, Haraoka K, Sun X, Morita H, et al. (2005) Studies on unfolded $\beta 2$-microglobulin at C-terminal in dialysisrelated amyloidosis. Kidney Int 67: 314-320.

8. Motomiya $Y$, Higashimoto $Y$, Uji Y, Suenaga G, Ando Y (2015) Cterminal unfolding of an amyloidogenic $\beta 2$-microglobulin fragment: $\Delta N 6 \beta 2 \mathrm{M}$-microglobulin. Amyloid 22: 54-60.

9. Linke RP, Hampl H, Lobeck H, Ritz E, Bommer J, et al. (1989) Lysine-specific cleavage of $\beta 2$-microglobulin in amyloid deposits associated with hemodialysis. Kidney Int 36: 675-681.

10. Esposito $G$, Michelutti R, Verdone $G$, Viglino $P$, Hernández $H$, et al. (2009) Removal of the $\mathrm{N}$-terminal hexapeptide from human $\beta 2$ microglobulin facilitates protein aggregation and fibril formation. Protein Sci 9: 831-845.

11. Myers SL, Jones S, Jahn TR, Morten JI, Tennent GA, et al. (2006) A systematic study of the effect of physiological factors on $\beta 2$ microglobulin amyloid formation at neutral $\mathrm{pH}$. Biochem 45: 2311-2321.

12. Yamamoto S, Yamaguchi I, Hasegawa K, Tsutsumi S, Goto Y, et al. (2004) Glycosaminoglycans enhance the trifluoroethanol-induced extension of $\beta 2$-microglobulin-related amyloid fibrils at a neutral pH. J Am Soc Nephrol 15: 126-133.

13. Borysik AJ, Morten IJ, Radford SE, Hewitt EW (2007) Specific glycosaminoglycans promote unseeded amyloid formation from $\beta 2$-microglobulin under physiological conditions. Kidney Int 72: 174-181.

14. Fukasawa K, Higashimoto Y, Motomiya Y, Uji Y, Ando Y (2016) Influence of heparin molecular size on the induction of C-terminal unfolding in 32-microglobulin. Mol Biol Res Commun 5: 225-232.

15. Fukasawa K, Higashimoto $Y$, Ando $Y$, Motomiya $Y$ (2017) Selection of DNA aptamer that blocks the fibrillogenesis of a proteolytic amyloidogenic fragment $32 \mathrm{M}$. Ther Apher Dial 22: 61-66. 